\title{
Migration of an Ingested Fish Bone to the Submandibular Gland: A Case Report and Literature Review
}

\author{
Jinhua Ma ${ }^{a}$ Yahui Sun ${ }^{b}$ Baoqiang Dai ${ }^{a}$ Hongqin Wang ${ }^{a}$ \\ aDepartment of Otolaryngology, Cangzhou Central Hospital, Cangzhou, China; \\ ${ }^{b}$ Department of General Surgery, Hebei Medical University Fourth Affiliated Hospital, \\ Shijiazhuang, China
}

\section{What Is It about?}

Fish bones are among the most common foreign bodies that get lodged in the upper digestive tract, where they may be easily located on routine inspection and removed. The forcible swallowing of food may lead to the migration of a fish bone to the surrounding tissues. Migration most commonly occurs to the soft tissues of the neck, but migration to the submandibular gland has rarely been reported. Here, we reported a case in which a 58-year-old woman accidentally got a fish bone stuck in her pharynx.

\section{Keywords}

Foreign body · Pharynx · Foreign body migration · Submaxillary gland

\section{Abstract}

Background: Fish bone is one of the most common foreign bodies that gets lodged in the upper digestive tract, often located in the tonsil, epiglottis, pear-shaped fossa, and esophagus, where it may be easily located on routine inspection and removed. The forcible swallowing of food such as rice balls after ingesting fish bones by mistake may lead to the migration of the fish bone from the pharynx, throat, or esophagus to the surrounding tissues. Migration most commonly occurs to the soft tissues of the neck, even to the thyroid gland, but migration to the submandibular gland has rarely been reported. Conclusions: Foreign body ingestion may cause a series of complications and endanger a patient's life. Cases require high awareness and attentiveness on the part of the first physician to diagnose and manage the condition, and appropriate health education should be imparted to the patient. 


\section{Established Facts}

- Migration of an ingested fish bone to the submandibular gland has rarely been reported.

\section{Novel Insights}

- Ultrasonic scanning can be performed when laryngoscopy yields negative results.

- This paper reports a case examined with ultrasonic scanning and treated with surgery, with a good outcome.

\section{Introduction}

Here we report the case of a woman who accidentally got a bone of a fish stuck in her throat. Migration of an ingested fish bone to the submandibular gland has been rarely reported. In this case, laryngoscopy yielded negative results. With the help of ultrasonic scanning, we found and removed the bone.

\section{Case Report}

A 58-year-old woman, who is fond of eating fish, accidentally got a bone of a fish she caught 90 days ago stuck in her throat. She swallowed steamed bread and leeks repeatedly, as she had pain on swallowing, with no immediate relief. Hence, she visited the local hospital where an examination was conducted of the pharynx, followed by electronic laryngoscopy, and nothing was found. Thereafter, she felt relief without any treatment. She began to feel discomfort in the right submandibular gland after 80 days and reported for treatment at our hospital. The computed tomography (CT) images showed a linear high-density image of the right submaxillary gland. A hyperechogenic line was shown on the ultrasonic image of the gland, of about $1.39 \times 0.39 \mathrm{~cm}$, and was diagnosed as a foreign body (Fig. 1).

After admission, relevant examinations were conducted, and she underwent an exploration of the right neck root and removal of the foreign body under general anesthesia, with no surgical contraindications. Probing of the submaxillary gland revealed a sharp and hard foreign body about $1.5 \mathrm{~cm}$ long, which was a fish bone. During the smooth operation, a plier was used to completely remove the 1.5 -cm-long fish bone, which was measured to be the same size as on the ultrasonic image (Fig. 2). The incision healed by first intention, and the suture was removed after 1 week. During 2 months of follow-up the patient showed no symptoms of pain or foreign body sensation.

\section{Discussion}

Similar to this case, most patients undertake improper measures after swallowing foreign bodies, such as swallowing rice balls, leeks, and steamed bread. Owing to the feeling of the retained foreign body, this patient swallowed rice balls forcibly and cared little about it, causing the foreign body to move. Sometimes, the foreign body migrates to surrounding or distant tissues by way of penetrating the pharynx and esophagus. 


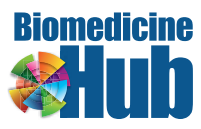

\begin{tabular}{|c|c|}
\hline \\
\hline DOI: $10.1159 / 000501873$ & $\begin{array}{l}\text { (c) } 2019 \text { The Author(s). Published by S. Karger AG, Basel } \\
\text { www.karger.com/bmh }\end{array}$ \\
\hline
\end{tabular}
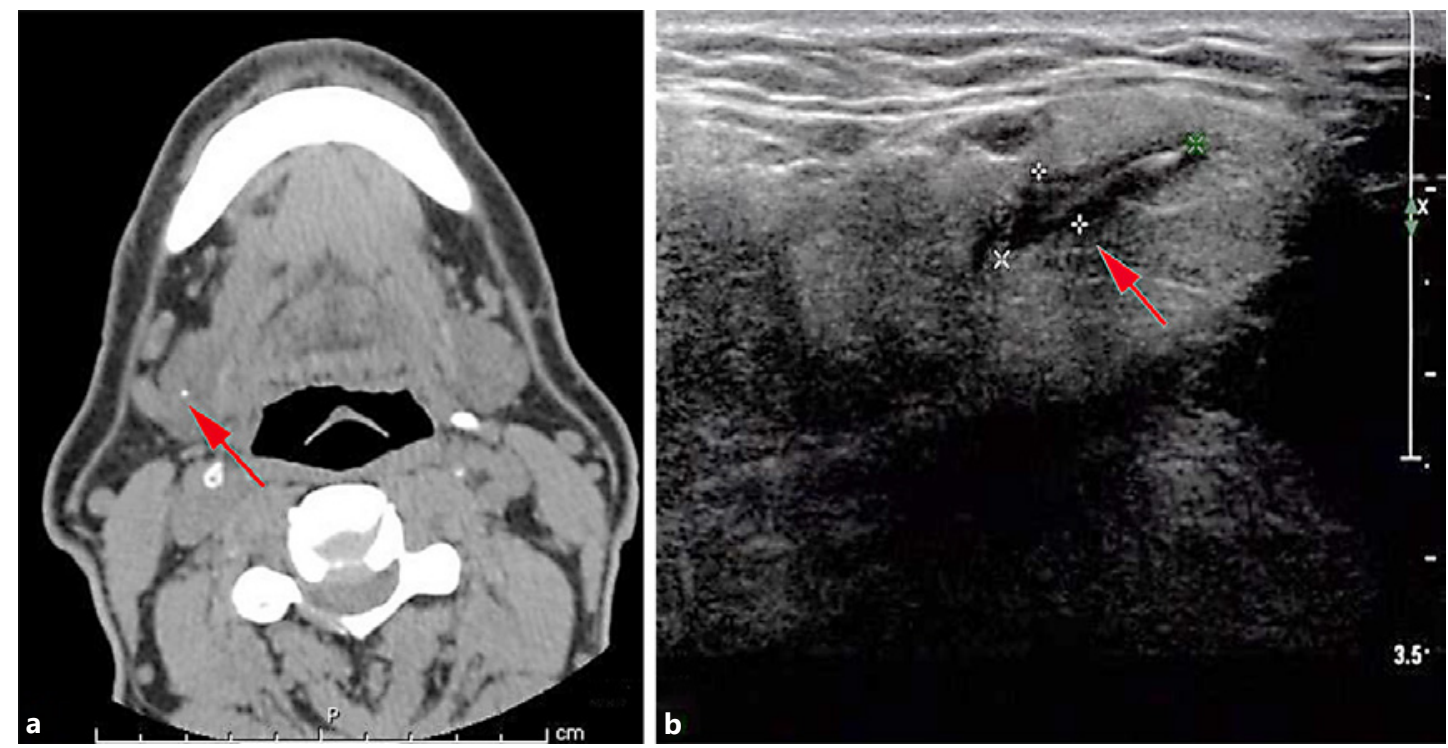

Fig. 1. a CT image showing a foreign body fish bone (arrow). b The ultrasonic image of the neck showing a hyperechogenic line, about $1.39 \mathrm{~cm} \times 0.39 \mathrm{~cm}$ (arrow).
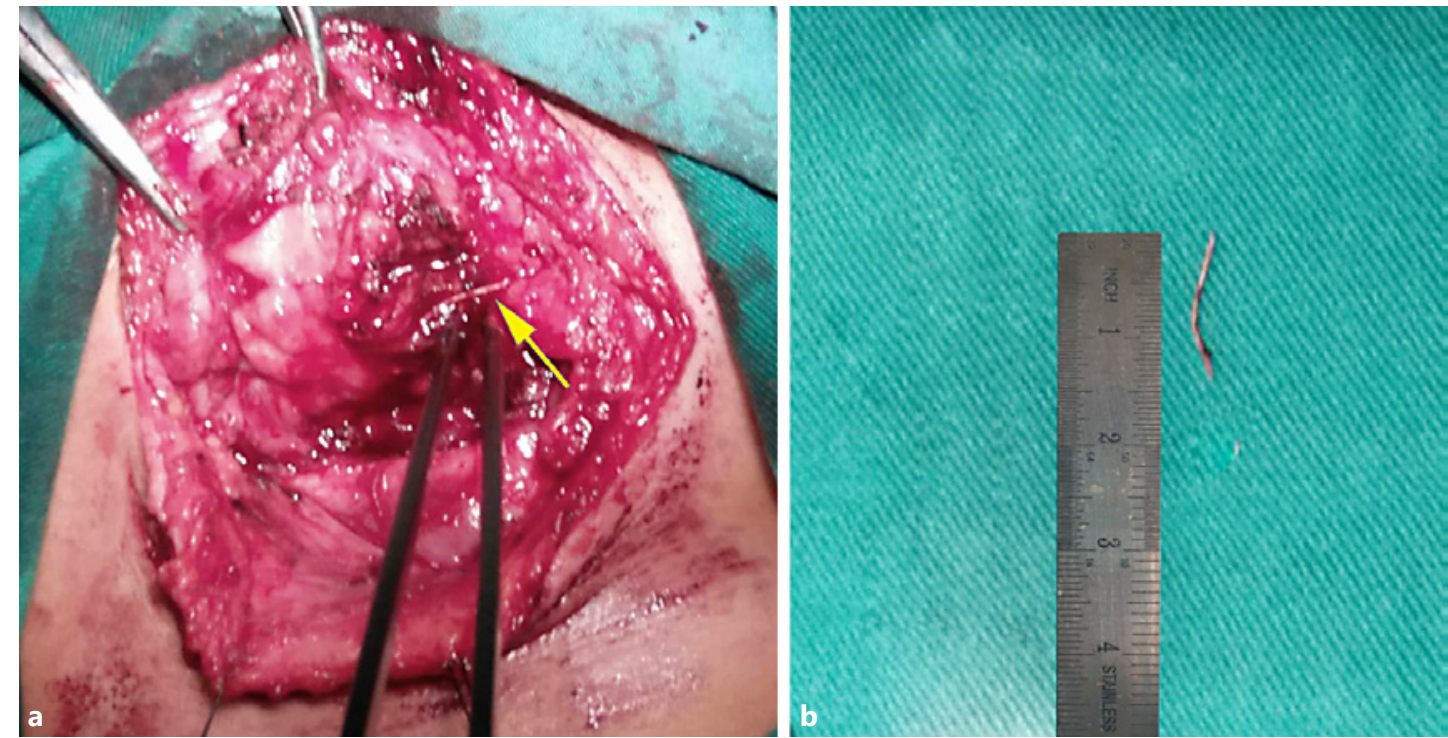

Fig. 2. a The intraoperative picture of a fish bone about $1.5 \mathrm{~cm}$ long (arrow). b The extracted fish bone was about $1.39 \mathrm{~cm}$ long, consistent with the measurement on the ultrasonic image.

The patient experienced a pricking sensation in the throat after swallowing the fish bone by mistake, accompanied by neck swelling and pain. However, no abnormality was found on throat and esophagus examination. In this situation, clinicians should consider possible foreign body migration. The doctor must not only focus on the throat and subsequently deny the existence of a foreign body from the laryngoscopy results. In similar future cases with no positive finding on throat examination, ordering an ultrasonic scan or CT of the neck is advisable. In order to avoid the occurrence of serious complications, doctors should fully explain the risks of not extracting the fish bone in time with the suitable precautions to be taken in case of an occurrence, and also stress on the need for follow-up visits. 
Migration of the fish bone to the submaxillary gland must be considered as a differential diagnosis when a patient reports a history leading comprehensively to a diagnosis of submaxillary pain. Advanced imaging examinations such as CT and ultrasonic scanning may be conducted to confirm the diagnosis of a foreign body.

Although there has been a case report on a fish bone lodged in the neck that disappeared on CT after the patient underwent conservative treatment for 9 months [1], potential complications may emerge and physical removal is recommended. Foreign bodies occurring in the upper digestive tract $[2,3]$ are easily found and removed in a timely manner. Ultrasonic scanning must be performed when laryngoscopy yields negative results. As shown in this case, it is not easy to find them when they lie in the submaxillary gland. This condition may cause a series of complications and endanger a patient's life $[4,5]$. Hence, the first physician must be aware and attentive to diagnose and manage the condition correctly, and impart appropriate health education to the patient. Most of all, it is necessary to inform people of the importance of eating fish carefully.

\section{Statement of Ethics}

The study protocol was approved by Cangzhou Central Hospital, and the subject gave her informed consent before enrollment.

\section{Disclosure Statement}

The authors have no conflicts of interest to declare.

\section{Funding Sources}

This research did not receive any specific grant from funding agencies in the public, commercial, or not-for-profit sectors.

\section{Author Contributions}

J.M. and Y.S. wrote the paper. B.D. structured the images. H.W. reviewed and edited the manuscript. All authors read and approved the report.

\section{References}

1 Canbay E, Prinsley P. The case of the disappearing fish bone. J Otolaryngol. 1995 Dec;24(6):375-6.

2 Loh KS, Tan LK, Smith JD, Yeoh KH, Dong F. Complications of foreign bodies in the esophagus. Otolaryngol Head Neck Surg. 2000 Nov;123(5):613-6.

3 Evans RM, Ahuja A, Rhys Williams S, Van Hasselt CA. The lateral neck radiograph in suspected impacted fish bones - does it have a role? Clin Radiol. 1992 Aug;46(2):121-3.

4 Joshi AA, Bradoo RA. A foreign body in the pharynx migrating through the internal jugular vein. Am J Otolaryngol. 2003 Mar-Apr;24(2):89-91.

5 Chee LW, Sethi DS. Diagnostic and therapeutic approach to migrating foreign bodies. Ann Otol Rhinol Laryngol. 1999 Feb;108(2):177-80. 